\title{
BNREL
}
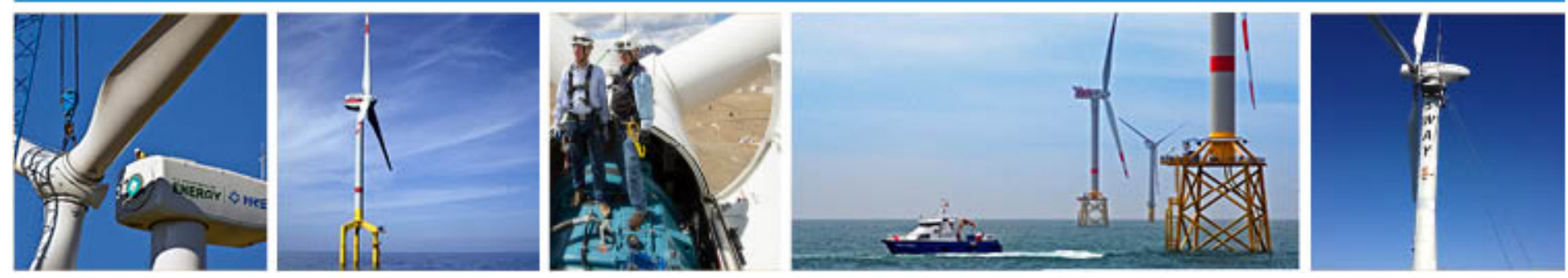

\section{Design and Analysis for a Floating Oscillating Surge Wave Energy Converter}

\section{Preprint}

Y-H. Yu, Y. Li, K. Hallett, and C. Hotimsky National Renewable Energy Laboratory

To be presented at ASME $201433^{\text {rd }}$ International Conference on Ocean, Offshore and Arctic Engineering San Francisco, CA

June 8-13, 2014

NREL is a national laboratory of the U.S. Department of Energy Office of Energy Efficiency \& Renewable Energy Operated by the Alliance for Sustainable Energy, LLC

This report is available at no cost from the National Renewable Energy Laboratory (NREL) at www.nrel.gov/publications.

\section{Conference Paper}

NREL/CP-5000-61283

March 2014

Contract No. DE-AC36-08G028308 


\section{NOTICE}

The submitted manuscript has been offered by an employee of the Alliance for Sustainable Energy, LLC (Alliance), a contractor of the US Government under Contract No. DE-AC36-08GO28308. Accordingly, the US Government and Alliance retain a nonexclusive royalty-free license to publish or reproduce the published form of this contribution, or allow others to do so, for US Government purposes.

This report was prepared as an account of work sponsored by an agency of the United States government. Neither the United States government nor any agency thereof, nor any of their employees, makes any warranty, express or implied, or assumes any legal liability or responsibility for the accuracy, completeness, or usefulness of any information, apparatus, product, or process disclosed, or represents that its use would not infringe privately owned rights. Reference herein to any specific commercial product, process, or service by trade name, trademark, manufacturer, or otherwise does not necessarily constitute or imply its endorsement, recommendation, or favoring by the United States government or any agency thereof. The views and opinions of authors expressed herein do not necessarily state or reflect those of the United States government or any agency thereof.

This report is available at no cost from the National Renewable Energy Laboratory (NREL) at www.nrel.gov/publications.

Available electronically at http://www.osti.gov/scitech

Available for a processing fee to U.S. Department of Energy and its contractors, in paper, from:

U.S. Department of Energy

Office of Scientific and Technical Information

P.O. Box 62

Oak Ridge, TN 37831-0062

phone: 865.576 .8401

fax: 865.576 .5728

email: mailto:reports@adonis.osti.gov

Available for sale to the public, in paper, from:

U.S. Department of Commerce

National Technical Information Service

5285 Port Royal Road

Springfield, VA 22161

phone: 800.553 .6847

fax: 703.605.6900

email: orders@ntis.fedworld.gov

online ordering: http://www.ntis.gov/help/ordermethods.aspx 


\section{DESIGN AND ANALYSIS FOR A FLOATING OSCILLATING SURGE WAVE ENERGY CONVERTER}

\author{
Yi-Hsiang Yu \\ National Renewable Energy Laboratory \\ Golden, CO, USA \\ Email: Yi-Hsiang.Yu@nrel.gov \\ Kathleen Hallett \\ National Renewable Energy Laboratory \\ Golden, CO, USA \\ Email: Kathleen.Hallett@nrel.gov
}

\author{
Ye Li \\ National Renewable Energy Laboratory \\ Golden, CO, USA \\ Email: Ye.Li@nrel.gov \\ Chad Hotimsky \\ National Renewable Energy Laboratory \\ Golden, CO, USA \\ Email: Chad.Hotimsky@nrel.gov
}

\begin{abstract}
This paper presents a recent study on the design and analysis of an oscillating surge wave energy converter (OSWEC). A successful wave energy conversion design requires balance between the design performance and cost. The cost of energy is often used as the metric to judge the design of the wave energy conversion (WEC) system, which is often determined based on the device's power performance; the cost of manufacturing, deployment, operation, and maintenance; and environmental compliance. The objective of this study is to demonstrate the importance of a cost-driven design strategy and how it can affect a WEC design. A set of three oscillating surge wave energy converter designs was analyzed and used as examples. The power generation performance of the design was modeled using a time-domain numerical simulation tool, and the mass properties of the design were determined based on a simple structure analysis. The results of those power performance simulations, the structure analysis, and a simple economic assessment were then used to determine the costefficiency of selected OSWEC designs. Finally, we present a discussion on the environmental barrier, integrated design strategy, and the key areas that need further investigation.
\end{abstract}

\section{KEYWORDS}

Wave energy; oscillating surge device; cost of energy

\section{INTRODUCTION}

The development of marine and hydrokinetic (MHK) devices that can extract energy from ocean energy resources has gained increasing interest in recent years. Studies have shown that wave energy is one of the most abundant sources for marine hydrokinetic energy in the United States, and recent estimates indicated that the U.S. wave energy resource is 2,600 $\mathrm{TWh} /$ year, from which $400 \mathrm{TWh} /$ year of electricity could be generated [1]. However, one of the major challenges is that the cost of energy that is generated by wave energy converters (WECs) is high, and improving WEC designs to be more costefficient is essential for the technologies to be successful, particularly in the early development stages [2].

The U.S. Department of Energy (DOE) Water Power Program has, therefore, established a reference model (RM) project to benchmark a set of different MHK technologies, including wave, tidal current, river current, and ocean current energy. The objectives of the RM project are to: 1) provide designs for several MHK devices that could be used to roughly gauge the status of the technology and its readiness for commercial application; 2) identify the areas where additional research could be best applied to accelerate technology development to commercial readiness. To achieve this goal, the RM project team developed an integrated, cost-oriented design strategy to balance the performance design with economic assessment [3].

In this paper, the objective is to demonstrate the importance of a cost-driven design strategy and how it can affect a WEC design. We analyzed three oscillating surge wave energy converter (OSWEC) designs and used the study as the examples. The power generation performance of the design was modeled using a time-domain numerical simulation tool. A structural analysis was conducted to determine the mass 
properties. We then used the results of those power performance simulations, structure analyses and a simple economic assessment to judge the design and economic viability for selected OSWECs. Finally, we present a discussion on the environmental barrier, the integrated design strategy, and key areas that need further investigation for evaluating the cost of energy of WEC designs.

\section{DEVICE DESIGN CONCEPT}

Several wave energy conversion systems that utilize the surge motion of waves to generate electrical power have been proposed by manufacturers, including Oyster, EB-Frond, WaveRoller, and Langlee. Because of the potential risk of permitting and regulation issues at near-shore shallow water regions [4] and the better wave resource at deep water sites [5], the study was focused on deep-water $(50 \mathrm{~m}-100 \mathrm{~m})$ surge designs, where the devices were moored to the seabed.
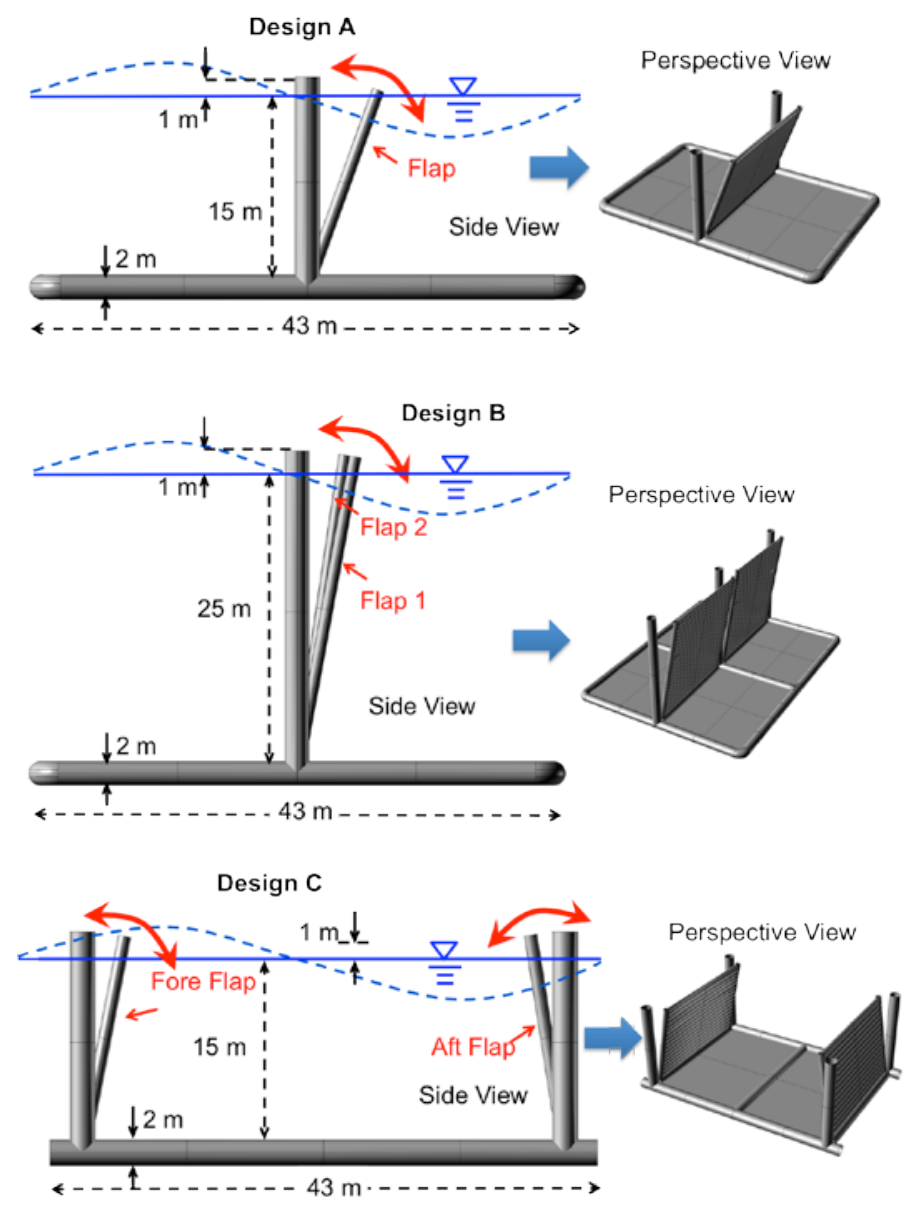

Figure 1. Schematic of selected OSWEC designs

Three OSWECs were selected in this study, for which the structural analysis and the power performance calculation for each design were performed. The orientation for selected OSWEC designs is shown in Figure 1. The flap was designed to rotate against the supporting frame to convert wave energy into electrical power from the relative rotational motion, induced by incoming waves. All three designs used a $25-\mathrm{m}$-wide flap, and the distance from the top of the flap to the mean water surface (freeboard) was equal to $1 \mathrm{~m}$. The dimensions for the OSWEC designs are listed in Table 1, and a brief summary for each OSWEC design is given below:

- Design A is a simple single-flap OSWEC system with a flap height of $16 \mathrm{~m}$.

- Design B has two 26-m-high flaps, which sit side-by-side (Figure 1). The purpose of the design was to increase the height and the total width of the device to reduce the wave diffraction lost under long waves so as to improve the power generation performance.

- Design C was inspired by the Langlee design [5], which used a fore flap and an aft flap to convert wave energy. In our study, the flap height was $16 \mathrm{~m}$, and the hinge-to-hinge distance between the two flaps was equal to $37 \mathrm{~m}$.

Table 1. List of Dimensions for the OSWEC Designs

\begin{tabular}{|l|c|c|c|}
\hline Design & A & B & C \\
\hline Number of flaps & 1 & 2 & 2 \\
\hline Flap width & $25 \mathrm{~m}$ & $25 \mathrm{~m}$ & $25 \mathrm{~m}$ \\
\hline Flap height (freeboard) & $16 \mathrm{~m}(1 \mathrm{~m})$ & $26 \mathrm{~m}(1 \mathrm{~m})$ & $16 \mathrm{~m}(1 \mathrm{~m})$ \\
\hline Flap thickness & $1 \mathrm{~m}$ & $1 \mathrm{~m}$ & $1 \mathrm{~m}$ \\
\hline Frame and shaft diameter & $2 \mathrm{~m}$ & $2 \mathrm{~m}$ & $2 \mathrm{~m}$ \\
\hline Structure width & $29.5 \mathrm{~m}$ & $57 \mathrm{~m}$ & $29.5 \mathrm{~m}$ \\
\hline Structure length & $43 \mathrm{~m}$ & $43 \mathrm{~m}$ & $43 \mathrm{~m}$ \\
\hline Structure height & $18 \mathrm{~m}$ & $28 \mathrm{~m}$ & $18 \mathrm{~m}$ \\
\hline
\end{tabular}

Note that all the flaps were connected to a 2-m-diameter rotational shaft, rotating against the supporting frame. The supporting frame was assumed to have an outer diameter of $2 \mathrm{~m}$, and the total length of the device structure for all the OSWEC designs was $43 \mathrm{~m}$. In addition, bottom plates were attached to the frame, and it was found to be effective, because it increased the frame added mass and stabilized the frame, so that the device power performance was improved.

Because the power performance of the OSWEC highly depends on the mooring configuration, particularly for designs $\mathrm{A}$ and $\mathrm{B}$, both slack mooring and taut mooring configurations were considered in this study. For reference purposes, the three OSWEC systems were also modeled by assuming the frame was rigidly connected to the seabed to investigate the loss of energy caused by the mooring connection.

\section{POWER PERFORMANCE ANALYSIS}

Modeling a WEC device involves simulating the interaction between waves, the WEC device motion, and the power takeoff (PTO) mechanism. A radiation and diffraction method is often used [6], particularly for predicting the device power performance and for optimizing the design. Typically, the method solves the device system dynamics in time domain, based on a given PTO damping representation and the hydrodynamics forces obtained from a frequency-domain solution. 


\section{Time-Domain Numerical Method}

The device system dynamic response was calculated by solving the Cummins equation [7], often used to represent the equation of motion for marine systems. The equation of motion for the floating-body system around the center of gravity can be given as

$m \ddot{X}=F_{e x}+F_{\text {rad }}+F_{P T o}+F_{v}+F_{B}+F_{m}$,

where $\ddot{\boldsymbol{X}}$ is the (translational and rotational) acceleration of the device, $\boldsymbol{m}$ is the mass matrix, $\boldsymbol{F}_{\boldsymbol{e x}}$ is the wave excitation force, $\boldsymbol{F}_{\boldsymbol{r a d}}$ is the force vector due to wave radiation, $\boldsymbol{F}_{\boldsymbol{P} \text { To }}$ is the PTO force, $\boldsymbol{F}_{\boldsymbol{v}}$ is the viscous damping force, $\boldsymbol{F}_{\boldsymbol{B}}$ is the net buoyancy restoring force, and $\boldsymbol{F}_{\boldsymbol{m}}$ is the force due to mooring connection. The remainder of this section describes each of these terms in further detail.

Irregular waves are often characterized using a wave spectrum that describes the wave energy distribution over a range of wave frequencies. The irregular excitation force can be written as the real part of an integral term in frequency,

$\boldsymbol{F}_{\boldsymbol{e x}}(t)=\operatorname{Re}\left(\int_{0}^{\infty} \sqrt{2 S(\omega)} \boldsymbol{F} \boldsymbol{X}(\omega) e^{i(\omega t+\phi)} d \omega\right)$

where Re denotes the real part of the function, $S$ is the wave spectrum, and $\phi$ is a random phase. Based on the Cummins equation, the irregular radiation term can be calculated by

$\boldsymbol{F}_{\text {rad }}(t)=-\boldsymbol{A}_{\infty} \ddot{\boldsymbol{X}}-\int_{0}^{t} \boldsymbol{K}(t-\tau) \dot{\boldsymbol{X}}(\tau) d \tau$

where $\boldsymbol{A}_{\infty}$ is the added mass matrix at infinite frequency, $\dot{\boldsymbol{X}}$ is the velocity of the body, and $\boldsymbol{K}$ is the impulse response function.

Generally, the effect of viscosity on the system dynamics for a WEC device needs to be considered, and neglecting the effect may lead to overestimating the power generation performance of the system, particularly when a linear model is applied. A common way of modeling the viscous damping effect is to add a (Morison-equation-type) quadratic damping term to the equation of motion,

$F_{V}=0.5 C_{d} \rho A_{D}\left(\dot{X}-V_{0}\right)\left|\dot{X}-V_{0}\right|$

where $\boldsymbol{C}_{\boldsymbol{d}}$ is the viscous drag coefficient, $\boldsymbol{A}_{\boldsymbol{D}}$ is the characteristic area, and $\boldsymbol{V}_{\mathbf{0}}$ is the undisturbed flow velocity. However, the viscous damping coefficient for the device needs to be carefully selected [4,5]. In this study, a drag coefficient of 8 was selected for the flap [8] and a drag coefficient of 4 was used for the heave motion of the plate [9], which was attached to the frame.

The mooring load was represented using a linear quasistatic mooring stiffness, which can be calculated by
$F_{m}=-K_{m} X$

where $\boldsymbol{K}_{\boldsymbol{m}}$ is the stiffness matrix for the mooring system.

The PTO mechanism was represented as a linear springdamper system, where the generated power was proportional to the relative motion and velocity,

$\boldsymbol{F}_{\text {PTo }}=-K_{P T O} \boldsymbol{X}_{\text {rel }}-C_{P T O} \dot{\boldsymbol{X}}_{\text {rel }}$,

where $K_{\boldsymbol{P T O}}$ is the stiffness of the system, $C_{\boldsymbol{P T O}}$ is the damping coefficient, and $\boldsymbol{X}_{\text {rel }}$ and $\dot{\boldsymbol{X}}_{\text {rel }}$ are the relative motion and velocity between the two bodies. Note that we did not optimize $K_{P T O}$ and assumed $K_{\text {PTO }}$ is equal to 0 in the study.

\section{WEC-Sim Model}

WEC-Sim is an open-source, computer-aided engineering tool developed for the analysis and optimization of WECs. The tool is currently being developed by the National Renewable Energy Laboratory and Sandia National Laboratories [10,11].

In the WEC-Sim model, a frequency-domain boundary element method (BEM), WAMIT [12], was applied to model the hydrodynamics of the system by solving the velocity potential. The corresponding hydrodynamic coefficients, obtained from the BEM simulation, along with viscous damping, mooring, and the PTO mechanism were converted into time-varying forces in the pre-processing module. The time-varying six degrees-of-freedom hydrodynamic responses and the corresponding power generation of the system were then obtained by solving Eq. (1) using the MATLAB Simulink/SimMechanics Toolbox with a $4^{\text {th }}$-order Runge-Kutta algorithm for time marching.

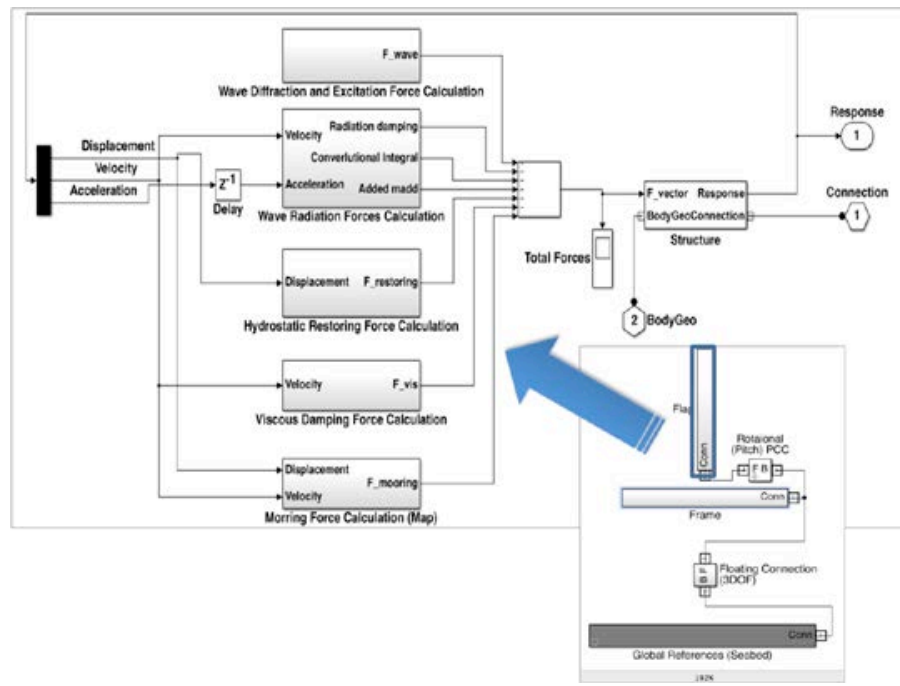

Figure 2. An example of a WEC-Sim model for simulating a floating WEC device and the top level of hydrodynamics modules

Figure 2 shows an example of using WEC-Sim to simulate a floating WEC system and the top level of hydrodynamics 
modules for the WEC-Sim model. Each separate module on the right side of the figure corresponds to the hydrodynamics calculation of wave radiation, excitation, net buoyancy restoring, viscous damping, and mooring forces.

\section{WEC-Sim Model Validation}

To validate the numerical model, WEC-Sim was applied to simulate a bottom-hinged OSWEC design (Figure 3). All the mass properties and dimensions (Table 2) were given based on the experimental study of Hoff [13]. The WEC-Sim simulation was performed at three different peak periods $\left(\mathrm{T}_{\mathrm{p}}\right)$ and four different significant wave heights $\left(\mathrm{H}_{\mathrm{s}}\right)$. For each case, the simulation duration was $125 \mathrm{~T}_{\mathrm{p}}$ long with a ramp time of $25 \mathrm{~T}_{\mathrm{p}}$ and a time step size of $0.01 \mathrm{~T}_{\mathrm{p}}$.
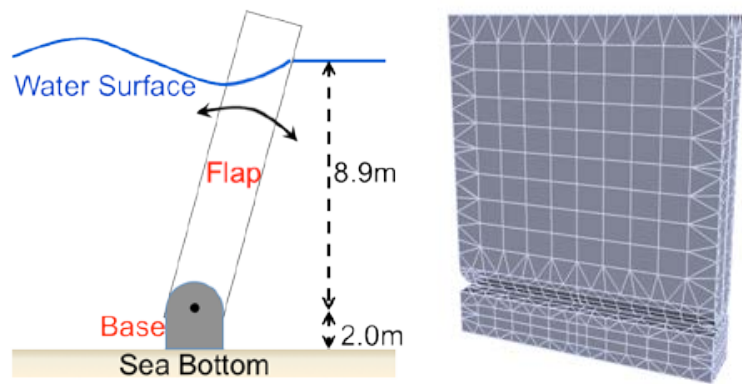

Figure 3. Schematic of a bottom-hinged OSWEC and mesh (half of the flap) used for the hydrodynamics calculations

Table 2. Mass Properties and Dimensions

\begin{tabular}{|l|c|}
\hline Parameters & Values (Unit) \\
\hline Dimensions (width x thickness) & $18 \mathrm{~m} \mathrm{x} \mathrm{1.8} \mathrm{m}$ \\
\hline Hinge to water surface & $8.9 \mathrm{~m}$ \\
\hline Moment of Inertia (at Hinge) & $1.85 \times 10^{6} \mathrm{kgm}^{2}$ \\
\hline Restoring Stiffness (at Hinge) & $6.4 \mathrm{MNm} / \mathrm{rad}$ \\
\hline
\end{tabular}

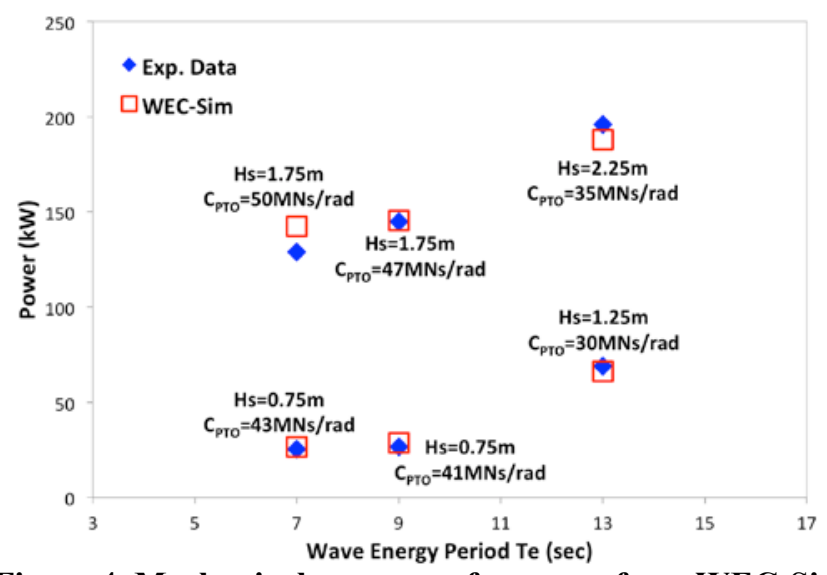

Figure 4. Mechanical power performance from WEC-Sim and experimental data (in full scale)

To compare WEC-Sim simulation results with those obtained from existing experimental measurement data [13], the averaged mechanical power was calculated. The values are plotted against the energy period $T_{e}$ in Figure 4, where $T_{e}$ is approximately 1.16 times of $\mathrm{T}_{\mathrm{p}}$ [14]. Overall, the numerical simulations results agreed well with those measurements from the wave tank test.

\section{DEVICE STRUCTURE DESIGN}

This section presents a preliminary structural analysis to determine the mass properties of the OSWEC designs. Each design contained one or two flaps and a supporting frame that was made of steel tubes. Each flap was assumed made of fiberglass tubes and was connected to a steel rotational shaft.

When a WEC is deployed under operation, all structural components endure not only the physical stresses imparted by the hydrodynamic pressure that is a product of water depth, but also the stresses from the force of waves as they pass over the device and drive the PTO system. The structural calculations were first performed using the pressure distribution data from WAMIT, where the force and moment distributions over each of the WEC fiberglass and steel tubes were evaluated. For simplicity, the tube was divided into multiple "bins" and simple beam theory was applied to calculate the moment distribution over the tube. Each cylinder tube was designed to withstand its maximum internal moment under an extreme wave amplitude of $\mathrm{A}=10 \mathrm{~m}$. Figure 5 shows an example of the pressure distribution and the corresponding moment distribution on one of the flaps for design B.
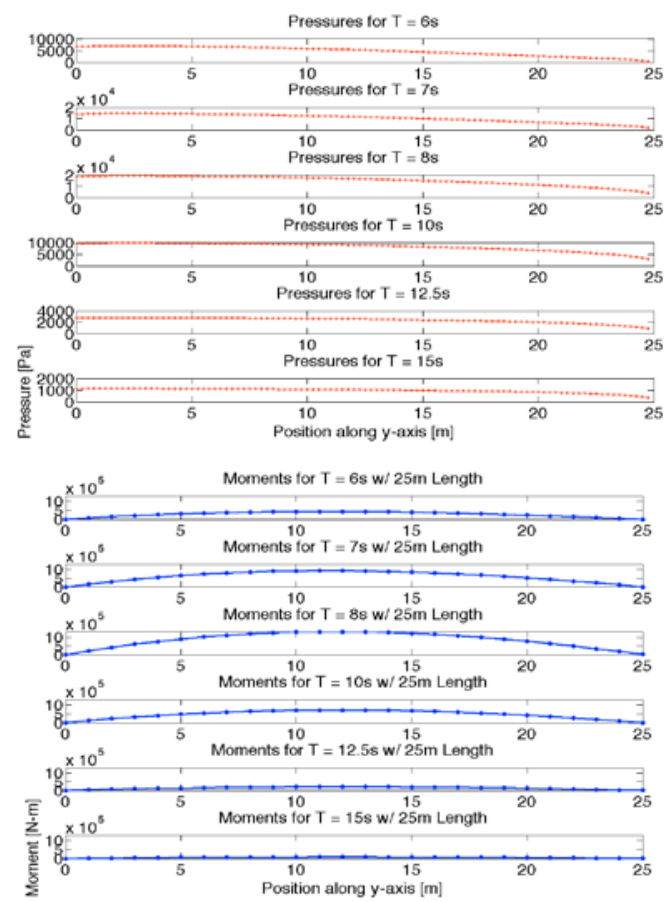

Figure 5. Hydrodynamic pressure distribution on a flap tube (left); corresponding moment distributions (right)

Several other checks were also required to ensure that the tubes will hold up to adverse stress conditions apart from transverse bending caused by hydrodynamic pressures (buckling). In addition, the thickness of the tube was also constrained by its displacement, which was limited to no more than $0.5 \mathrm{~m}$ under the given moment distribution. Linear 
displacement was assumed with thickness, so direct proportionality was used to find the final thickness necessary for the design. Note that a dynamic factor of safety was applied to all calculations, which was set at a conservative value of 2.0. More details on the structural design methodology were described in [15].

Based on the structural analysis, we determined the thickness of the fiberglass and steel tubes. Additionally, the bottom plate thickness was determined by following the plate design for a two-body floating point absorber [3]. The mass properties of the selected OSWEC designs are listed in Table 3, which were obtained from SolidWorks mass properties calculations. Note that the listed values for the flap and shaft only accounts for the mass properties for a single flap.

Table 3. List of Design Mass Properties

\begin{tabular}{|l|l|c|c|c|}
\hline \multicolumn{2}{|c|}{ Design } & A & B & C \\
\hline \multirow{3}{*}{$\begin{array}{l}\text { Flap \& } \\
\text { Shaft }\end{array}$} & Fiberglass Mass (Ton) & 90 & 112 & 90 \\
\cline { 2 - 5 } & Steel Mass (Ton) & 64 & 64 & 64 \\
\cline { 2 - 5 } & CG (m) & $(0,0,-10)$ & $(0,0,-15)$ & $( \pm 18.5,0,-10)$ \\
\cline { 2 - 5 } & MOI $\left(10^{6} \mathrm{kgm}^{2}\right)$ & 14.11 & 17.30 & 14.11 \\
\hline \multirow{3}{*}{$\begin{array}{l}\text { Supporting } \\
\text { Frame }\end{array}$} & Steel Mass (Ton) & 322 & 870 & 351 \\
\cline { 2 - 5 } & CG (m) & $(0,0,-15)$ & $(0,0,-23)$ & $(0,0,-14)$ \\
\cline { 2 - 5 } & MOI $\left(10^{6} \mathrm{kgm}^{2}\right)$ & 67.66 & 188.86 & 61.30 \\
\hline
\end{tabular}

CG: Center of gravity

MOI: Moment of inertia at the CG in pitch

\section{MODELING OF A FLOATING OSWEC}

\section{Numerical Model Setup}

WEC-Sim was used to model the hydrodynamic response of the selected OSWEC designs and calculate the corresponding power performance. The model setup in WEC-Sim for different designs is shown in Figure 6.
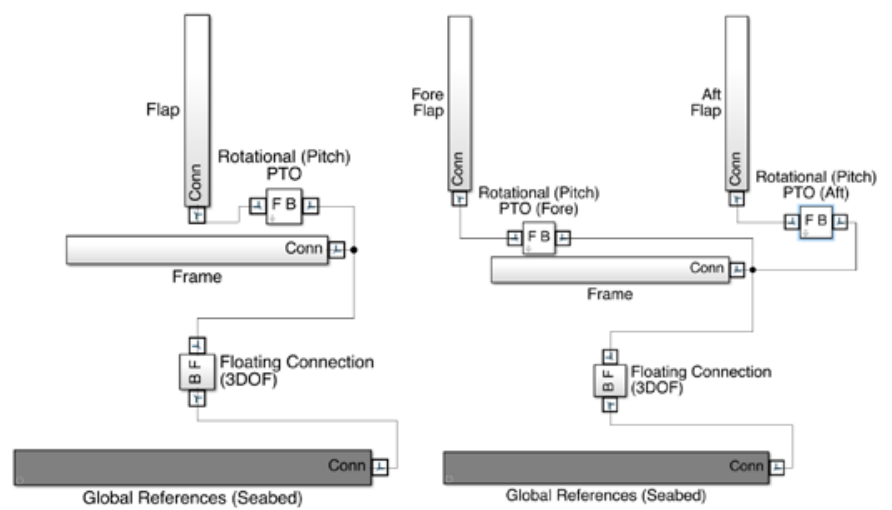

Figure 6. WEC-Sim model setup for designs A \& B (left) and design $\mathbf{C}$ (right)

For each design, the simulation was performed for a range of irregular sea states, which were characterized by $\mathrm{H}_{\mathrm{s}}$ and $\mathrm{T}_{\mathrm{p}}$, and were represented using a Brechtschneider spectrum. The hydrodynamic response of the device was simulated in the time domain for a duration of $125 \mathrm{~T}_{\mathrm{p}}$ with a ramp time of $25 \mathrm{~T}_{\mathrm{p}}$ and a maximum time step size of $0.01 \mathrm{~T}_{\mathrm{p}}$.
In the simulations, the supporting frame was ballasted so that the device was located at its equilibrium position without any pre-tension when the device was connected to slack mooring lines. On the other hand, the frame was ballasted to the weight of the frame when the device was connected to taut moorings, where the pre-tension was equal to the total net buoyancy force from the flap and shaft. Accordingly, the moment of inertia for the slack moored and taut moored cases was adjusted. For designs with a slack mooring configuration, a mooring stiffness of $40 \mathrm{kN} / \mathrm{m}$ was specified for the surge direction to keep the device in position. For designs with a taut mooring connection, an optimal mooring stiffness was selected based on device power performance for a typical sea state $\left(\mathrm{T}_{\mathrm{e}}=8.7 \mathrm{sec} ; \mathrm{Hs}=1.75 \mathrm{~m}\right)$ from the reference site.

An optimal velocity-dependent PTO damping force for each sea state was determined by tuning the device performance with different PTO damping coefficients. Note that we assumed the same PTO damping value for the fore flap and the aft flap when modeling design $\mathrm{C}$.

\section{Power Matrix and Estimated AEP Calculation}

The annual energy production for a WEC can be determined based on the wave statistics at a reference site, the device performance power matrix, and the loss between absorbed mechanical power and electrical power output.

The wave statistic at the reference site is often represented by the joint probability distribution (JPD) of the waves, characterized by $\mathrm{H}_{\mathrm{s}}$ and $\mathrm{T}_{\mathrm{e}}$ (or $\mathrm{T}_{\mathrm{p}}$ ). The JPD at Humboldt Bay, CA (Table 4) was used in the study, and it was obtained based on the measurements from a nearby National Data Buoy Center buoy (\#46212).

Table 4. JPD for the Wave Resource at Humboldt Bay

\begin{tabular}{|c|c|c|c|c|c|c|c|c|c|}
\hline \multicolumn{10}{|c|}{ Wave Statistic (JPD) } \\
\hline & & \multicolumn{8}{|c|}{ Energy Period Te (s) } \\
\hline & & 4.7 & 6.7 & 8.7 & 10.7 & 12.7 & 14.7 & 16.7 & 18.7 \\
\hline \multirow{6}{*}{$\frac{\underline{E}}{\underline{n}}$} & 0.75 & $0.0 \%$ & $4.6 \%$ & $5.4 \%$ & $2.8 \%$ & $1.4 \%$ & $1.1 \%$ & $1.3 \%$ & $0.0 \%$ \\
\hline & 1.75 & $0.0 \%$ & $7.4 \%$ & $12.2 \%$ & $10.0 \%$ & $5.8 \%$ & $3.4 \%$ & $2.0 \%$ & $0.0 \%$ \\
\hline & 2.75 & $0.0 \%$ & $1.6 \%$ & $7.2 \%$ & $7.5 \%$ & $6.3 \%$ & $3.6 \%$ & $2.0 \%$ & $0.0 \%$ \\
\hline & 3.75 & $0.0 \%$ & $0.1 \%$ & $1.3 \%$ & $2.3 \%$ & $2.9 \%$ & $2.3 \%$ & $1.2 \%$ & $0.0 \%$ \\
\hline & 4.75 & $0.0 \%$ & $0.0 \%$ & $0.1 \%$ & $0.4 \%$ & $0.6 \%$ & $0.9 \%$ & $0.8 \%$ & $0.0 \%$ \\
\hline & 5.75 & $0.0 \%$ & $0.0 \%$ & $0.0 \%$ & $0.0 \%$ & $0.0 \%$ & $0.0 \%$ & $0.0 \%$ & $0.0 \%$ \\
\hline
\end{tabular}

The power generation performance of WECs in irregular seas is often represented using a power matrix. The mechanical power matrix was obtained by modeling the OSWEC design at each given sea state and by calculating the averaged power performance. To estimate the electrical power matrix, we multiplied the mechanical power matrix with a PTO conversion efficiency and limited the maximum electrical power output at the rated power (also referred to as capacity) to reduce the size of generator and cost. The electrical power that can be generated by the OSWEC design under each given sea state can be obtained from 
$P_{e}=P_{m} \times \eta_{1}$

where $P_{m}$ and $P_{e}$ are the estimate mechanical and electrical power that can be generated under each given sea state, and $\eta_{1}$ is the PTO efficiency that accounts for the losses between absorbed mechanical power and electrical power output.

We assumed a hydraulic PTO system was used for the OSWEC designs and the conversion efficiency was $80 \%$ [16]. The rated power was estimated based on a capacity factor of $30 \%$, and details of the electrical power matrix calculation were described in [3]. An example of the resulting electrical power matrix for design A with a taut mooring connection is shown in Table 5. The annual averaged electrical power $P_{a e}$ was then obtained by summing the product of the electrical power matrix and the JPD for the reference site.

Table 5. Electrical Power Matrix for Design A (taut)

\begin{tabular}{|c|c|c|c|c|c|c|c|}
\hline \multicolumn{8}{|c|}{ Electrical Power Matrix (kW) } \\
\hline & & \multicolumn{6}{|c|}{ Energy Peak Period (s) } \\
\hline & & 6.7 & 8.7 & 10.7 & 12.7 & 14.7 & 16.7 \\
\hline \multirow{5}{*}{$\frac{\widehat{\underline{\underline{E}}}}{\underline{\underline{n}}}$} & 0.75 & 16.98 & 22.12 & 22.08 & 18.89 & 15.88 & 12.85 \\
\hline & 1.75 & 71.66 & 83.58 & 76.26 & 63.47 & 54.20 & 45.17 \\
\hline & 2.75 & 169.69 & 205.19 & 152.37 & 120.75 & 103.18 & 86.12 \\
\hline & 3.75 & 330.54 & 346.23 & 287.67 & 195.02 & 162.62 & 135.70 \\
\hline & 4.75 & 346.23 & 346.23 & 346.23 & 305.12 & 230.05 & 192.02 \\
\hline
\end{tabular}

\section{Parametric Studies}

The power generation performance for the selected OSWEC designs was calculated based on the methodology described in the previous section. To compare the power generation performance for the OSWEC designs with different mooring settings, the resulting annual averaged electrical power output for different scenarios is plotted in Figure 7. Note that, for design $\mathrm{C}$, we did not consider a taut-moored system in the study because the slack-mooring configuration worked well. In addition, the fixed frame results are also included.

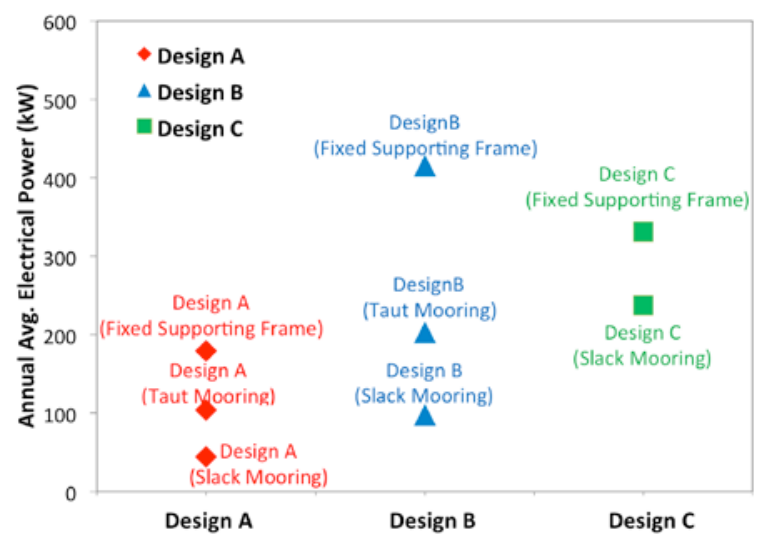

Figure 7. Annual averaged electrical power output for different OSWEC designs

As expected, the power generation increased as the number of flaps was increased (designs B and C) for the same mooring configuration. Design B had better performance when the supporting frame was fixed. For each design, the fixed-frame system provided the best power generation performance. For designs $\mathrm{A}$ and $\mathrm{B}$, the taut mooring connection helped reduce the frame rotation. Therefore, the device with a taut-mooring connection performed better than the one with a slacked mooring system.

To further investigate the influence of the frame stability on the design power generation performance, we compared the $P_{\mathrm{e}}$ on a single flap for the selected floating design to the fixed frame simulation results. The values are plotted against different $T_{e}$ in Figure 8. In addition, the corresponding ratios between the optimal $\mathrm{C}_{\text {PTO }}$ values for the fixed frame cases and those used for the floating design cases were calculated. The ratios are listed in Table 6 .
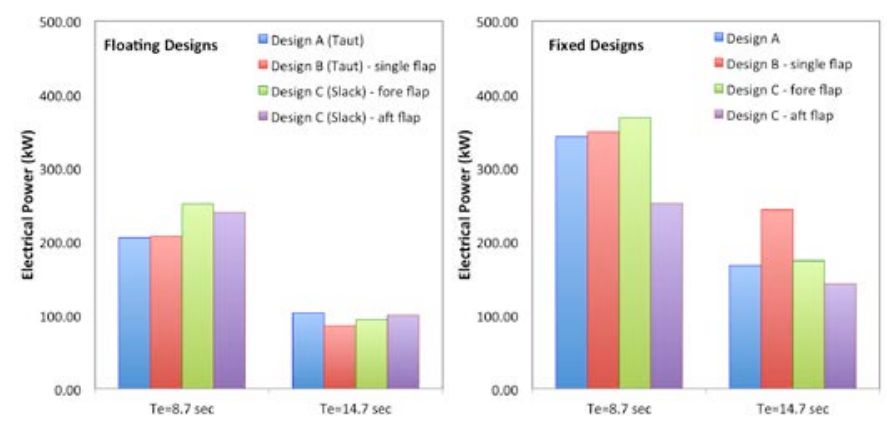

Figure 8. Electrical power output for selected floating and fixed frame OSWEC designs $\left(\mathrm{H}_{\mathrm{s}}=2.75 \mathrm{~m}\right)$

Table 6. Fixed Frame to Floating Designs Optimal $\mathrm{C}_{\text {pto }}$ Ratio

\begin{tabular}{|l|c|}
\hline Designs & $\begin{array}{l}\mathbf{C}_{\text {PTO (Fixed) }} / \\
\mathbf{C}_{\text {PTO(Floating) }}\end{array}$ \\
\hline Designs A (Fixed/Taut) & $4.2-12.5$ \\
\hline Designs B (Fixed/Taut) & $8.3-15$ \\
\hline Designs C (Fixed/Slack) & $1-1.5$ \\
\hline
\end{tabular}

When the flap rotated against a fixed frame, a larger optimal PTO damping value was applied. When the supporting frame was connected to mooring lines, the frame would rotate with the flap, and the optimal PTO damping value would be smaller, which reduced the device power generation performance, particularly for designs A and B. Because the fixed frame OSWEC operates as a terminator, a wider flap (e.g., design B) typically reduces the diffraction loss and performs better under a large wave period [17]. However, the power performance for design B decreased significantly when the frame was connected to moorings, particularly for large-wave period scenarios, where design $\mathrm{B}$ was less effective than design $\mathrm{A}$, as shown in Figure 8. The results also implied that the taut mooring connection was not very effective for a wider OSWEC design.

For design $\mathrm{C}$, the aft flap converted less energy than the fore flap due to wave diffraction from the fore flap when the frame was rigidly connected to the seabed. When design $\mathrm{C}$ was connected to slack moorings, the fore flap and the aft flap 
extract about the same amount of energy from waves. We believed that the distance between the fore and aft flaps resulted in a phase shift on the wave excitation force and increased the relative motion between the aft flap and the frame, which improved the power performance of the system. As a result, the power extraction loss due to the connection of moorings for design $\mathrm{C}$ with the slack moorings was minimized. Note that the complex nonlinear wave and flaps interaction, particularly for the aft flap, was not fully captured in the WECSim model. Neglecting those effects may lead to overestimating the device power output. Although design C's power generation performance predicted from WEC-Sim is promising, further analysis, such as experimental wave tank tests or computational fluid dynamics simulations, are needed to validate the results.

\section{DISCUSSION}

From a hydrodynamics point of view, the power generation performance of the OSWEC systems can be improved by increasing the flap height and width and by stabilizing the frame using a taut mooring connection or a fixed supporting frame structure. Design improvements that increase power generation performance often incur costs-increased capital costs and/or operation costs. The levelized cost of energy (LCOE) metric reflects the necessary tradeoffs between minimizing costs and maximizing energy production. In practice, LCOE is often used as the metric to judge the design and economic viability of an energy conversion system. Understanding LCOE and how to reduce it is essential to make renewable energy designs that are successful and competitive with other electricity resources. As a result, the cost implications of the design need to be addressed during the design process.

To assess the tradeoffs between improving power generation performance and lowering costs of the selected OSWEC designs, we evaluated the device annual energy production (AEP) to characteristic mass ratio. This ratio serves as a proxy for LCOE in the absence of detailed cost data. Because the study was focused on the floating OSWEC design, the fixed frame designs were excluded from the comparison. The estimated AEP [in megawatt-hours (MWh)] was calculated by

$A E P=P_{a e} \times 8766 \times \beta$,

where $\beta=\eta_{2} \times \eta_{3}$ is the parameter, accounting for the losses caused by transmission efficiency $\eta_{3}=0.98(98 \%)$ and device availability $\eta_{2}$. A device availability value of $95 \%$ was used for designs A and B [3]. Because design C contains a fore flap and an aft flap, we assumed the design will most likely require two sets of PTO systems, which may increase the downtime due to maintenance. A device availability value of $90 \%$ was therefore used for design $\mathrm{C}$.

The characteristic mass $\left(m_{c h}\right)$ of the device was determined from $m_{c h}=\left(m_{s}+m_{f}\right) \times \beta_{m}$,

where $m_{s}$ is the mass of the steel for the device, $m_{f}$ is an equivalent steel mass value for the fiberglass part, which was determined based on the cost difference between the fiberglass and the steel. We assumed $m_{f}$ was equal to 2.3 times the mass of the fiberglass used in the design. The value was selected based on the experience from the wind energy blade design. The variable $\beta_{\mathrm{m}}$ was used to account for the mooring cost. We assumed $\beta_{\mathrm{m}}$ was equal to 1.2 for a typical slack-moored floating WEC device. The value was determined from the Carbon Trust [18], which estimated the percent contributions to the cost of energy for early commercial WEC designs. For a taut-moored WEC device, we assumed the total cost of mooring and anchor was doubled [19], and $\beta_{\mathrm{m}}$ was therefore equal to 1.4 .

The AEP to characteristic mass ratio for different floating OSWEC designs are plotted in Figure 9. For designs A and B, the taut-moored system was more cost-efficient than the slackmoored system. Overall, design $\mathrm{C}$ had the best performance in terms of AEP per characteristic mass among all the floating OSWEC designs. However, the manufacturing and mooring cost (which are represented by the AEP to characteristic mass ratio) only represent about $30 \%$ of the WEC design cost [18]. The cost of the PTO system, deployment (installation), grid connection, and operation and maintenance (O\&M) also depend on the WEC device designs, which were not considered in the study. In addition, the design strategy may be altered because of environmental permitting and regulation.

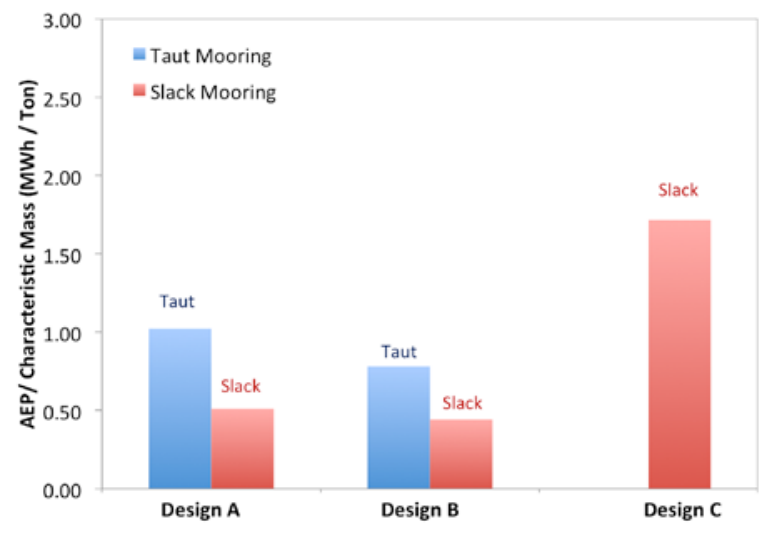

\section{Figure 9. AEP to characteristic mass ratio for selected OSWEC designs}

In fact, the original OSWEC design proposed in the RM project was a bottom-fixed system, in which the flap rotated with respect to a frame rigidly connected to the seabed. From the power generation performance point of view, the bottomfixed OSWEC designs also have greater power generation performance, as shown in the results presented in the previous section. However, the design was changed to a floating system before significant engineering or cost analysis was conducted, based on concerns raised by the environmental assessment [4]. 
The potential risk to the marine environment from the devices could have a significant effect on near-shore marine animals, habitats, and ecosystem processes, particularly for a commercial-scale deployment in shallow water (10- to $20-\mathrm{m}$ water depth) with sand bottom, where shoreline sediment drift and shore-form creation also depends on the incoming waves. One of the RM project objectives is to investigate the commercial application of the design. Therefore, the OSWEC design was changed to a floating system.

Because LCOE is often used to judge the design and economic feasibility of an energy conversion system, we suggested a more sophisticated iterative design strategy, proposed in the RM project [3], as shown in Figure 10. This approach involves four modules that can be used to determine the device design, considerations for manufacturing and deployment (M\&D), strategies for O\&M, and environmental constraints. These four modules can be used to estimate the parameters needed to calculate LCOE: AEP, capital expenditures (CapEx), and operational expenditures (OpEx).

Incorporating this multifaceted design strategy into the development process at an early stage, rather than exclusively focusing on the hydrodynamic performance, facilitates a more efficient path towards designing for an optimized LCOE. As shown in the study, changing the OSWEC design for different sizes will affect the structural design as well as the hydrodynamic power performance, which provides a different cost of energy for each design. Developing an optimal costefficient design and a pathway to reduce LCOE in the future are important for the success of wave energy technology.

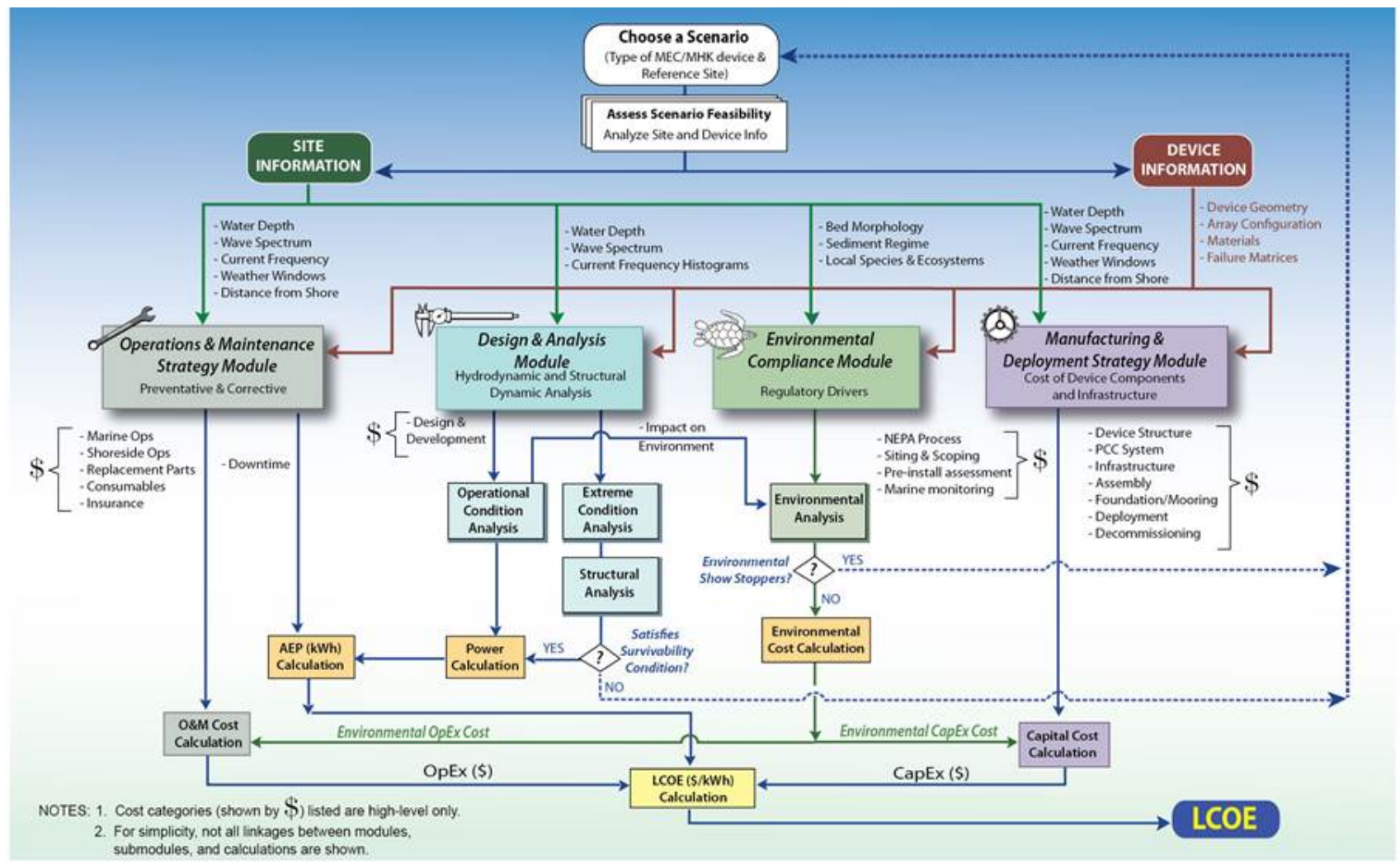

Figure 10. An iterative design strategy for WEC designs

\section{CONCLUSIONS AND FUTURE WORK}

The cost-efficiency for three OSWEC designs were evaluated in this paper by calculating the power generation performance of the designs using a time-domain numerical simulation tool and by evaluating the characteristic mass of the designs. The study also showed that it is essential to consider a cost-oriented design strategy to balance the performance design with economic assessment, as well as with the environmental issues. Incorporating this design strategy into the development process at an early stage can facilitate a more efficient path towards designing for an optimized LCOE. We used OSWEC as the example in this paper, and this multifaceted design strategy can be used by other ocean energy systems.

To fully understand the potential LCOE for WEC designs, further analyses are still needed, particularly for the extreme load prediction and the cost estimate for deployment and O\&M. Specifically:

- The WEC devices are designed to survive under extreme storm waves. The nonlinear extreme wave load is essential for the structural design. However, nonlinear wave and body interaction increase the complexity for estimating the extreme wave load on the device and on mooring lines. 
Further investigations on the extreme load measurement in a wave tank test and prediction in numerical simulations are needed.

- The evaluation of the cost and the strategy for deployment and O\&M is very difficult at this nascent stage in the wave energy industry. Most of the cost estimation methods and strategies for WEC deployment and O\&M come from experience with offshore oil and gas platforms and offshore wind energy experience. To date, no commercial wave energy farms have been deployed; representative data in these areas are not yet available and need to be investigated further.

\section{ACKNOWLEDGMENT}

This work was supported by the U.S. Department of Energy under Contract No. DE-AC36-08GO28308 with the National Renewable Energy Laboratory. Funding for the work was provided by the DOE Office of Energy Efficiency and Renewable Energy, Wind and Water Power Technologies. We would like to thank Vincent Neary from Sandia National Laboratories for his efforts and Andrea E. Copping from Pacific Northwest National Laboratory for her efforts on the RM project.

\section{REFERENCES}

[1] Jacobson P., Hagerman G., and Scott G., 2011, Mapping and Assessment of the United States Ocean Wave Energy Resource, Electric Power Research Institute.

[2] Weber J., 2012, "WEC Technology Readiness and Performance Matrix - finding the best research technology development trajectory," 4th International Conference on Ocean Energy, ICOE, Dublin, Ireland.

[3] Neary V. S., Previsic M., Jepsen R. A., Lawson M. J., Yu Y.-H., Copping A. E., Fontaine A. A., and Hallett K. C., 2014, Methodology for Design and Economic Analysis of Marine Energy Conversion (MEC) Technologies, Sandia National Laboratories, Albuquerque, NM.

[4] Copping A., Geerlofs S., and Hanna L., 2013, The Contribution of Environmental Siting and Permitting Requirements to the Cost of Energy for Wave Energy Devices, Pacific Northwest National Laboratory (PNNL), Richland, WA.

[5] Babarit A., Hals J., Muliawan M. J., Kurniawan A., Moan T., and Krokstad J., 2012, "Numerical Benchmarking Study of a Selection of Wave Energy Converters," Renew. Energy, 41, pp. 44-63.

[6] Li Y., and Yu Y.-H., 2012, "A Synthesis of Numerical Methods for Modeling Wave Energy Converter-Point Absorbers," Renew. Sustain. Energy Rev., 16(6), pp. 4352-4364.
[7] Cummins W., 1962, The Impulse Response Function and Ship Motions, David Taylor Model Dasin-DTNSRDC.

[8] Babarit A., Hals J., Kurniawan A., Muliawan M., Moan T., and Krokstad J., 2011, The NumWEC Project Selection: Numerical Estimation of Energy Delivery from a Selection of Wave Energy Converters, Statkraft, Trondheim, Norway.

[9] Nelessen A., 2012, CFD Analysis of Viscous Effects on Wave Energy Devices, SULI Report, National Renewable Energy Laboratory (NREL), Golden, CO.

[10] Ruehl K., Michelen C., Kanner S., Lawson M., and Yu Y.H., 2014, "Preliminary Verification and Validation of WEC-Sim, an Open Source Wave Energy Converter Design Tool," 33rd International Conference on Ocean, Offshore and Arctic Engineering, OMAE, San Francisco, CA, United States (Abstract accepted).

[11] Lawson M., Yu Y.-H., Nelessen A., Ruehl K., and Michelen C., 2014, "A Study on the Nonlinear Hydrodynamics of Wave Energy Converters," 33rd International Conference on Ocean, Offshore and Arctic Engineering, OMAE, San Francisco, CA, United States (Abstract accepted).

[12] Lee C., and Newman J., 2006, "WAMIT® User Manual," WAMIT, Inc.

[13] van't Hoff J., 2009, "Hydrodynamic Modelling of the Oscillating Wave Surge Converter," The Queen's University of Belfast.

[14] Beels C., Henriques J. C. C., Rouck J. De, Pontes M. T., De Backer G., and Verhaeghe H., 2007, "Wave energy resource in the North Sea," 7th European Wave and Tidal Energy Conference, Porto, Portugal.

[15] Hotimsky C., 2013, Marine Hydrokinetic Analysis of Wave Energy Converter Reference Model 5, SULI Report, National Renewable Energy Laboratory (NREL), Golden, CO.

[16] Cargo C. J., Plummer a. R., Hillis a. J., and Schlotter M., 2011, "Determination of optimal parameters for a hydraulic power take-off unit of a wave energy converter in regular waves," Proc. Inst. Mech. Eng. Part A J. Power Energy, 226(1), pp. 98-111.

[17] Gomes R., Lopes M., Henriques J., Gato L., and Falcão A., 2011, "A Study on the Wave Energy Conversion by Submerged Bottom-hinged Plates," 9th European Wave and Tidal Energy Conference, Southampton, UK.

[18] Carbon Trust, 2011, Accelerating Marine Energy.

[19] Ridge I. M. L., Banfield S. J., and Mackay J., 2010, "Nylon fibre rope moorings for wave energy converters," Oceans 2010, IEEE, Seattle, WA, United States, pp. 1-10. 